\title{
Optical Coherence Tomography Evaluation of Retinal Nerve Fiber Layer and Ganglion Cell Layer Thickness before and after Argon Laser in Treatment of Diabetic Retinopathy \\ Mohamed Tarek Abdelmoneim, Abdulla Mohamed Elamin, Alaa Abdelmongy Sadaka, Hossam Abdelfattah Husein* \\ Department of Ophthalmology, Faculty of Medicine, Aswan University \\ * Corresponding author: Hossam Abdelfattah Husein, Mobile: (+20) 01026808348, E-mail: dr.hossamhmmad@ yahoo.com
}

\begin{abstract}
Background: Diabetic retinopathy (DR) is one of the most common microvascular complications of diabetes with the potential to cause severe vision loss and blindness and a devastating effect on quality of life.

Objective: Discuss the macular ganglion cell and retinal nerve fiber layer (RNFL) changes after laser treatment as a management of diabetic retinopathy.

Patients and Methods: This study was carried out on 55 eyes of 35 patients designed as a prospective, interventional case series at Sohag Ophthalmic Diagnostic Laser Unit between January 2016 and March 2017. A complete ophthalmologic examination was performed, including best-corrected visual acuity (BCVA) using the ETDRS charts, intraocular pressure (IOP) measurement, slit-lamp biomicroscopic examination, fundus examination, fluorescein angiography, and 3D optical coherence tomography (OCT) 2000.

Results: The value of RNFL (superior and total) in the GRID group is more than in the pan-retinal photocoagulation (PRP) group which increased at 1 month post laser (not significant) then significantly decreased at 6 month follow up. The value of RNFL (inferior) in the GRID group is more than in the PRP group which significantly increased at 1 month post laser then decreased at 6 month follow up table 4.

Conclusion: Significant ganglion cell (GC) and RNLF decrease at the sixth month of follow-up can be attributed to axonal loss secondary to direct or indirect effects of PRP treatment. SD OCT is a very valuable tool to document the RNFL thickness changes following the argon laser photocoagulation.
\end{abstract}

Keywords: Optical coherence tomography, Retinal nerve fiber layer, Argon laser in treatment, Diabetic retinopathy

\section{INTRODUCTION}

Diabetes mellitus (DM) has become a global health problem fueled by increased caloric consumption and the resultant obesity epidemic ${ }^{(\mathbf{1})}$.

Retinal nerve fiber layer (RNFL) measurements using optical coherence tomography (OCT) programs for nerve head indicate that the highest degree of variability can be attributed to interpatient differences. The recently developed OCT provides the ophthalmologist with the opportunity to customize scans and to tailor a single scan circle to examine RNFL thickness. Custom scans can be useful to help the ophthalmologist differentiate normal from early glaucomatous peripapillary RNFL ${ }^{(2)}$.

Ganglion cell analysis (GCA) algorithm of Cirrus OCT can successfully detect and measure the thickness of the macular ganglion cell-inner plexiform layer (GCIPL) with excellent intervisit reproducibility ${ }^{(3)}$.

The use of laser photocoagulation in the treatment of diabetic retinopathy is one of the best examples in which laser energy revolutionized the treatment of a serious disease ${ }^{(4)}$.

Although pan-retinal photocoagulation (PRP) proved to be an effective treatment strategy for severe diabetic retinopathy, the laser intensity utilized is decided by the physician. Most physicians agree that laser intensity that causes damage to the entire retinal layer should be avoided. It was reported that a highintensity laser beam can cause destruction of the entire retinal layer, including ganglion cells (GC). Damage to GC results in loss of the RNFL and a sequential decrease in the peripapillary nerve fiber layer thickness (5).

Diabetic macular edema is associated with increased vascular leakage in the central part of the retina, and it is a feared complication of DM. For decades, diabetic macular edema was treated with focal/grid photocoagulation (ETDRS-Group 1987) in which laser shots are applied directly to leaking microaneurysms (focal treatment) or are delivered in a grid pattern on the thickened edematous part of the retina (grid treatment). In many subjects with diabetic macular edema, both of the mentioned modalities are often required and are performed during the same treatment session ${ }^{(6)}$.

\section{AIM OF THE WORK}

Discuss the macular ganglion cell and retinal nerve fiber layer changes after laser treatment as a management of diabetic retinopathy.

\section{PATIENTS AND METHODS}

This study was carried out on 55 eyes of 35 patients, designed as a prospective, interventional case series at the Sohag Ophthalmic Diagnostic Laser Unit between January 2016 and March 2017. A complete ophthalmologic examination was performed, including best-corrected visual acuity (BCVA) using the ETDRS charts, intraocular pressure (IOP) measurement, slitlamp biomicroscopic examination, fundus examination, fluorescein angiography, and 3D OCT 2000 (Topcon, Inc., Tokyo, Japan) 


\section{Ethical approval and written informed consent :}

An approval of the study was obtained from Aswan University Academic and Ethical Committee. Every patient signed an informed written consent for acceptance of the operation.

\section{PRP protocol:}

PRP was performed by single trained personnel. Multiple-session PRP used a conventional argon 514 $\mathrm{nm}$ green laser in three sessions, each 1 week apart. The area of laser coverage extended from one-disc diameter outside the vascular arcades up to the ora serrata in all four quadrants, sparing a one-disc diameter zone in the peripapillary zone. The laser burn size and pulse duration was $200-500 \mathrm{~mm}$ and $100 \mathrm{~ms}$, respectively, and placed at one burn-width apart $(300 \mathrm{~mm})$. The total number of burns was approximately 2000 .

\section{Grid protocol:}

Grid was performed by single trained personnel. Grid photocoagulation was applied to areas of diffuse leakage and capillary nonperfusion on fluorescein angiography. Focal laser settings were 50 to $100 \mu \mathrm{m}$ spot size, 50 to $100 \mathrm{~ms}$ pulse duration, and power titrated to whiten the microaneurysm. Grid laser settings were 50 to $200 \mu \mathrm{m}$ spot size, 50 to $100 \mathrm{~ms}$ pulse duration, and power titrated to achieve mild burn intensities. No burns were placed within 500 microns of disc. The laser burns were placed approximately two visible burn widths apart in the areas of the macular edema.

\section{GCC and RNFL Scanning Procedures:}

All OCT examinations were performed by a single, well-trained technician (under my observations). Optical coherence tomography macular scan and optic nerve head $(\mathrm{ONH})$ scan were performed using the Topcon SD-OCT model 2000 version 7.11 in fine analysis mode. The Topcon 3D OCT 2000 measures the RNFL thickness, the RGC with the IPL (GCIP), and the GCC. It uses raster scanning of a $7 \mathrm{~mm}^{2}$ area that is centered on the fovea with a scan density of 128 (horizontal) $\times 512$ (vertical) scans (Figure 1). The boundaries of the anatomical layers were determined by the program software using a validated, automated segmentation algorithm. The macular inner retinal layers (MIRL) analysis software detects the center of the fovea at the macular cube automatically, and selects a $6 \mathrm{~mm} \times 6 \mathrm{~mm}$ region centered at the foveal center. The software divides the macular square into a $6 \times 6$ grid containing 100 cells of $0.6 \mathrm{~mm} \times 0.6 \mathrm{~mm}$, to assess regional abnormalities in MIRL thickness. Average regional thickness of GCC, GCIP and RNFL in each cell was calculated and compared to the normative database of the device.
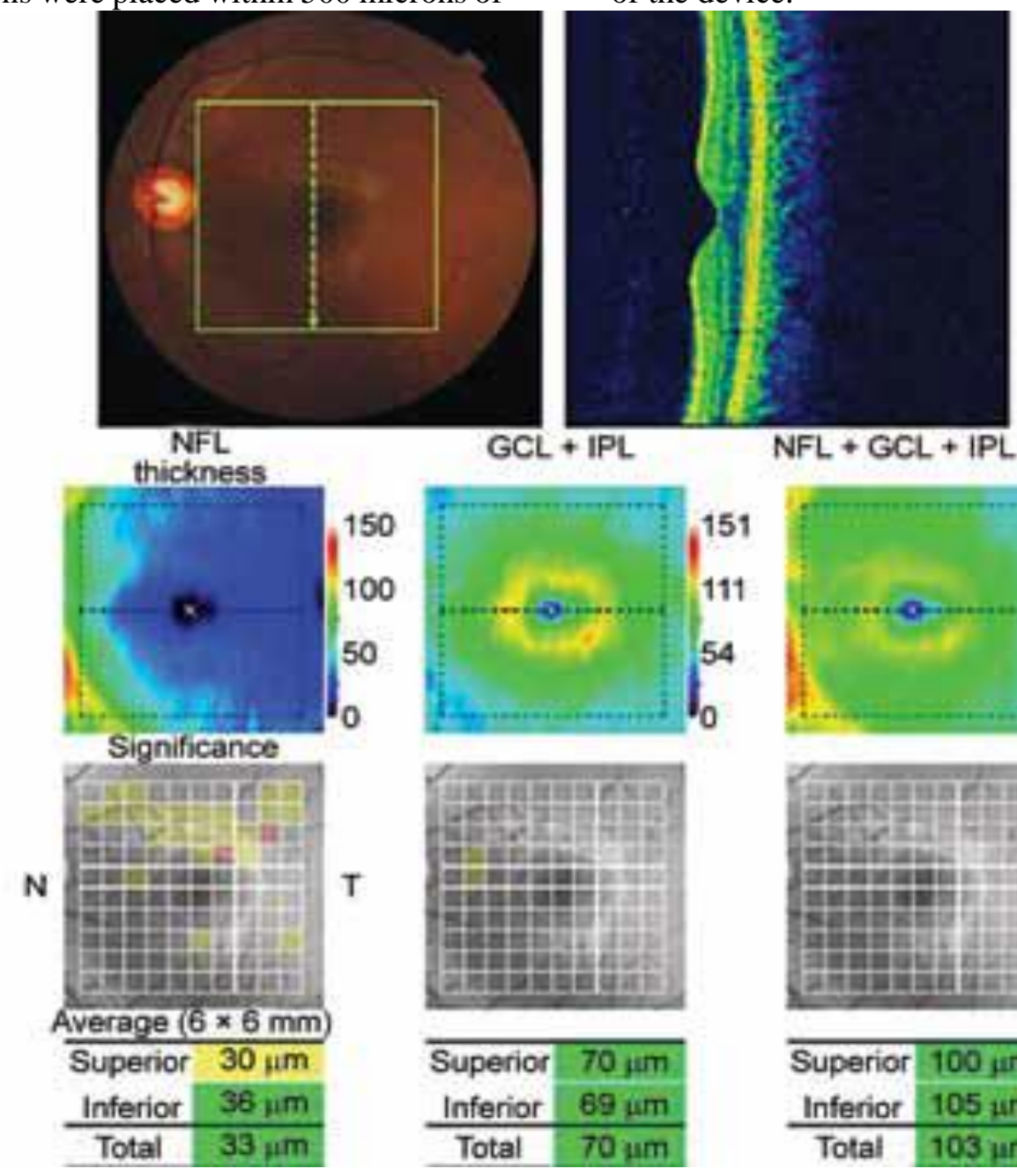

$\mathrm{GCL}+\mathrm{IPL}$
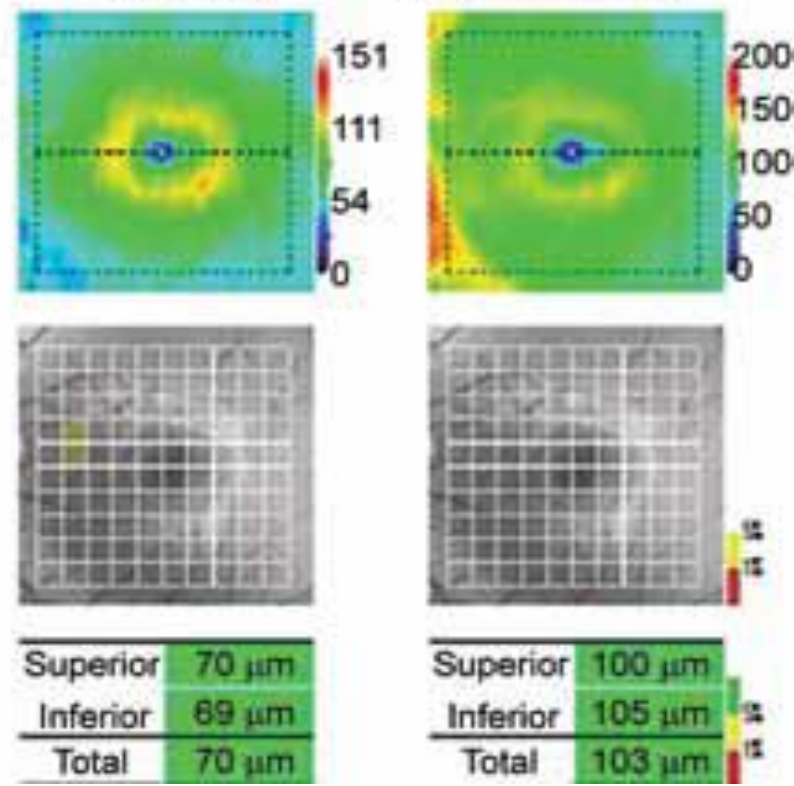

Figure (1): Macular scan using OCT (actual printout from Topcon model 2000 version 7.1)

As shown from figure (Figure 1) three dimensions optical coherence tomography 2000 calculate average regional thickness for RNFL, GCL+ (GCL + IPL), GCL++ (RNFL + GCL + IPL). Each cell is calculated 
and compared to the normative database of the device. The comparison result is displayed with the color in the legend on the right. The background image is red free image; D: Average thickness. From left to right, three average thicknesses of RNFL, GCL+ and GCL++. The top is "Superior" which means average in the upper half area, the middle is "Inferior" which means average in the lower half area, and the bottom is "Total' which means average in the total area. Each average thickness is compared to the normative data and displayed according to color; asymmetry map. From left to right, subtraction thickness maps covering $6 \mathrm{~mm} \times 6 \mathrm{~mm}$ area of RNFL, GCL+ and GCL++ are shown. The subtraction is performed between two points which symmetrically lie with respect to the center horizontal line. In the upper half, the value in each point is calculated such that thickness of the point is subtracted from the thickness of the corresponding line-symmetry point below and vice versa. Blue indicates that the thickness of the point is thinner than that of the corresponding point.

In ONH scan protocol, the reference plane height of disk topography is 120 microns. The peripapillary RNFL (pRNFL) thickness was calculated as the distance between the anterior and posterior RNFL borders in a $3.45 \mathrm{~mm}$ radius ring centered on the optic disk. The average pRNFL thickness corresponding to the superior and inferior hemifields was measured (figure 2). follows:

The criteria for determining scan quality were as

1. Image quality more than 70 (according to the manufacturer).

2. A clear fundus image with clear foveal pit, $\mathrm{ONH}$ and scan circle before and during image acquisition.

3. Even and dense color saturation in all retinal layers, with red color visible in retinal pigment epithelium and a continuous scan pattern without missing areas.

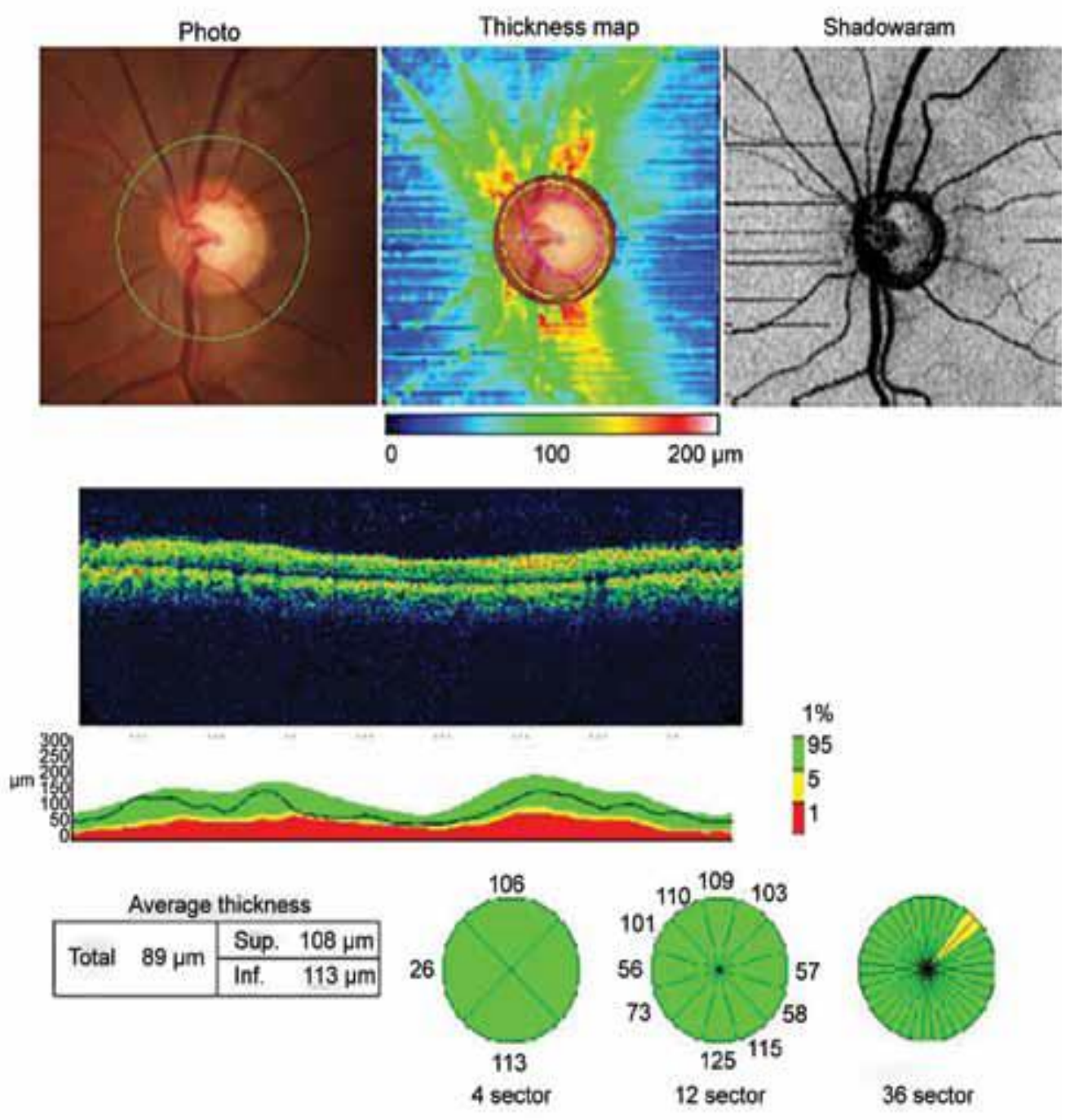

Figure. (2): Optic nerve head scan using OCT (actual printout from Topcon model 2000 version 7.1)

\section{Follow-up protocol:}


Follow-up examinations were scheduled at 1 and 6 months after PRP. A complete ophthalmologic examination was performed at each follow-up.

\section{Statistical analysis}

Recorded data were analyzed using the statistical package for social sciences, version 20.0 (SPSS Inc., Chicago, Illinois, USA). Quantitative data were expressed as mean \pm standard deviation (SD). Qualitative data were expressed as frequency.

Independent-samples t-test of significance was used when comparing between two means. P-value $<0.05$ was considered significant.

\section{RESULTS}

Fifty-five eyes of 35 patients were enrolled in this study but because of occurrence of uncorrectable error in OCT machine we completed follow up of only 29 eyes of 18 patients.

Table 1 shows the demographic and clinical characteristics of the patients.
Table (1): Patient demographic and clinical characteristics.

\begin{tabular}{ll}
\hline Characteristics & Value \\
\hline No. of patients & 18 \\
No. of eyes & 29 \\
Age (yrs.) & $52.17 \pm 14.15^{*}$ \\
Male / female & $8 / 10$ \\
D M type 1 / D M type 2 & $5 / 13$ \\
\hline * Values are presented a the mean \pm standard deviation
\end{tabular}

* Values are presented as the mean \pm standard deviation.

Comparison between peripapillary RNFL in the PRP group, and the GRID group:

The value of peripapillary RNFL in the GRID group is more than at the PRP group which increased at 1 month post laser then decreased at 6 month follow up and the difference is almost not significant table 2 .

Table (2): Comparison between peripapillary RNFL in the PRP group, and the GRID group.

\begin{tabular}{|c|c|c|c|c|c|}
\hline \multirow{2}{*}{\multicolumn{2}{|c|}{$\begin{array}{c}\text { Comparative } \\
\text { parameters }\end{array}$}} & \multirow{3}{*}{$\begin{array}{c}\begin{array}{c}\text { PRP } \\
\text { group }\end{array} \\
108.60 \\
\end{array}$} & \multirow{2}{*}{$\begin{array}{l}\text { GRD } \\
\text { group }\end{array}$} & \multicolumn{2}{|r|}{ Result } \\
\hline & & & & $P$ value & significance \\
\hline \multirow{2}{*}{$\begin{array}{l}\text { RNFL superior at the } \\
\text { baseline at the optic nerve. }\end{array}$} & Mean & & 136.33 & \multirow{2}{*}{0.01} & \multirow{2}{*}{ Significant } \\
\hline & Standard Deviation & 18.32 & 23.43 & & \\
\hline \multirow{2}{*}{$\begin{array}{l}\text { RNFL inferior at the baseline } \\
\text { at the optic nerve. }\end{array}$} & Mean & 106.21 & 104 & \multirow{2}{*}{0.66} & \multirow{2}{*}{ Not significant } \\
\hline & Standard Deviation & 27.35 & 14.94 & & \\
\hline \multirow{2}{*}{$\begin{array}{l}\text { RNFL total at the baseline at } \\
\text { the optic nerve. }\end{array}$} & Mean & 88.47 & 106.33 & \multirow{2}{*}{0.36} & \multirow{2}{*}{ Not significant } \\
\hline & Standard Deviation & 15.46 & 18.68 & & \\
\hline \multirow{2}{*}{$\begin{array}{l}\text { RNFL superior after } 1 \text { month } \\
\text { at the optic nerve. }\end{array}$} & Mean & 121.52 & 144.66 & \multirow{2}{*}{0.07} & \multirow{2}{*}{ Not significant } \\
\hline & Standard Deviation & 16.68 & 25.5 & & \\
\hline \multirow{2}{*}{$\begin{array}{l}\text { RNFL inferior after } 1 \text { month } \\
\text { at the optic nerve. }\end{array}$} & Mean & 118.39 & 110.83 & \multirow{2}{*}{0.35} & \multirow{2}{*}{ Not significant } \\
\hline & Standard Deviation & 26.81 & 32.65 & & \\
\hline \multirow{2}{*}{$\begin{array}{l}\text { RNFL total after } 1 \text { month at } \\
\text { the optic nerve. }\end{array}$} & Mean & 97.43 & 115.66 & \multirow{2}{*}{0.45} & \multirow{2}{*}{ Not significant } \\
\hline & Standard Deviation & 16.69 & 18.38 & & \\
\hline \multirow{2}{*}{$\begin{array}{l}\text { RNFL superior after } 6 \\
\text { months at the optic nerve. }\end{array}$} & Mean & 120.86 & 141.66 & \multirow{2}{*}{0.12} & \multirow{2}{*}{ Not significant } \\
\hline & Standard Deviation & 20.17 & 26.39 & & \\
\hline \multirow{2}{*}{$\begin{array}{l}\text { RNFL inferior after } 6 \text { months } \\
\text { at the optic nerve. }\end{array}$} & Mean & 115.60 & 107.83 & \multirow{2}{*}{0.51} & \multirow{2}{*}{ Not significant } \\
\hline & Standard Deviation & 26.67 & 33.10 & & \\
\hline \multirow{2}{*}{$\begin{array}{l}\text { RNFL total after } 6 \text { months at } \\
\text { the optic nerve. }\end{array}$} & Mean & 94.52 & 112.66 & \multirow{2}{*}{0.04} & \multirow{2}{*}{ Significant } \\
\hline & Standard Deviation & 16.13 & 17.68 & & \\
\hline
\end{tabular}

\section{Comparison between GCL in the PRP group, and the GRID group.}

The value of GCL (Inferior and Total) at GRID group is more than at PRP group which increased significantly at 1 and 6 month follow up $(\mathrm{P}<0.05)$. The value of GCL (superior) at GRID group is more than at PRP group with no significant changes at base line, 1 or 6 months follow up table 3 . 
ejhm.journals.ekb.eg

\begin{tabular}{|c|c|c|c|c|c|}
\hline \multirow{2}{*}{\multicolumn{2}{|c|}{$\begin{array}{l}\text { Comparative } \\
\text { parameters }\end{array}$}} & \multirow{3}{*}{$\begin{array}{c}\begin{array}{c}\text { PRP } \\
\text { group }\end{array} \\
69.56 \\
\end{array}$} & \multirow{3}{*}{$\begin{array}{c}\begin{array}{c}\text { GRD } \\
\text { group }\end{array} \\
85.33 \\
\end{array}$} & \multicolumn{2}{|r|}{ Result } \\
\hline & & & & $P$ value & significance \\
\hline \multirow{2}{*}{$\begin{array}{l}\text { GLC superior at the } \\
\text { baseline. }\end{array}$} & Mean & & & \multirow{2}{*}{0.3} & \multirow{2}{*}{ Not significant } \\
\hline & Standard Deviation & 11.51 & 33.86 & & \\
\hline \multirow{2}{*}{$\begin{array}{l}\text { GLC inferior at the } \\
\text { baseline. }\end{array}$} & Mean & 65.34 & 79.83 & \multirow{2}{*}{0.007} & \multirow{2}{*}{ Significant } \\
\hline & Standard Deviation & 9.49 & 12.49 & & \\
\hline \multirow{2}{*}{$\begin{array}{l}\text { GLC total at the } \\
\text { baseline. }\end{array}$} & Mean & 68.30 & 84.5 & \multirow{2}{*}{0.02} & \multirow{2}{*}{ Significant } \\
\hline & Standard Deviation & 9.14 & 23.95 & & \\
\hline \multirow{2}{*}{$\begin{array}{l}\text { GLC superior after } 1 \\
\text { month. }\end{array}$} & Mean & 74.17 & 91 & \multirow{2}{*}{0.16} & \multirow{2}{*}{ Not significant } \\
\hline & Standard Deviation & 12.98 & 33.5 & & \\
\hline \multirow{2}{*}{$\begin{array}{l}\text { GLC inferior after } 1 \\
\text { month. }\end{array}$} & Mean & 67.91 & 86 & \multirow{2}{*}{0.007} & \multirow{2}{*}{ Significant } \\
\hline & Standard Deviation & 12.42 & 17.27 & & \\
\hline \multirow{2}{*}{$\begin{array}{l}\text { GLC total after } 1 \\
\text { month. }\end{array}$} & Mean & 73.04 & 93.33 & \multirow{2}{*}{0.003} & \multirow{2}{*}{ Significant } \\
\hline & Standard Deviation & 8.58 & 20.81 & & \\
\hline \multirow{2}{*}{$\begin{array}{l}\text { RNFL superior at the } \\
\text { macula after } 6 \text { months. }\end{array}$} & Mean & 71.60 & 89.66 & \multirow{2}{*}{0.07} & \multirow{2}{*}{ Not significant } \\
\hline & Standard Deviation & 12.20 & 33.21 & & \\
\hline \multirow{2}{*}{$\begin{array}{l}\text { RNFL inferior at the } \\
\text { macula after } 6 \text { months. }\end{array}$} & Mean & 66.47 & 84 & \multirow{2}{*}{0.0006} & \multirow{2}{*}{ Significant } \\
\hline & Standard Deviation & 12.51 & 17.29 & & \\
\hline \multirow{2}{*}{$\begin{array}{l}\text { RNFL total at the } \\
\text { macula after } 6 \text { months. }\end{array}$} & Mean & 69.82 & 90.83 & \multirow{2}{*}{0.001} & \multirow{2}{*}{ Significant } \\
\hline & Standard Deviation & 7.63 & 20.02 & & \\
\hline
\end{tabular}

Comparison between RNFL at the macula in the PRP group, and the GRID group.

The value of RNFL (superior and total) in the GRID group is more than in the PRP group which increased at 1 month post laser (not significant) then significantly decreased at 6 month follow up. The value of RNFL (inferior) in the GRID group is more than in the PRP group which significantly increased at 1 month post laser then decreased at 6 month follow up table 4.

Table (4) Comparison between RNFL at the macula in the PRP group, and the GRID group.

\begin{tabular}{|c|c|c|c|c|c|c|}
\hline \multirow{2}{*}{ Quadrant } & \multirow{2}{*}{$\begin{array}{c}\text { Time of } \\
\text { follow-up }\end{array}$} & \multirow{2}{*}{$\begin{array}{l}\text { Comparative } \\
\text { parameters }\end{array}$} & \multirow{2}{*}{ PRP group } & \multirow{2}{*}{$\begin{array}{l}\text { GRID } \\
\text { group }\end{array}$} & \multicolumn{2}{|r|}{ Result } \\
\hline & & & & & P value & significance \\
\hline \multirow{2}{*}{$\begin{array}{l}\text { RNFL superior } \\
\text { at macula. }\end{array}$} & \multirow[b]{2}{*}{$\begin{array}{l}\text { at the } \\
\text { baseline }\end{array}$} & Mean & 36.82 & 52.66 & \multirow[b]{2}{*}{0.19} & \multirow[b]{2}{*}{ Not significant } \\
\hline & & $\begin{array}{l}\text { Standard } \\
\text { Deviation }\end{array}$ & 11.57 & 31.35 & & \\
\hline \multirow[b]{2}{*}{$\begin{array}{l}\text { RNFL inferior } \\
\text { at macula. }\end{array}$} & \multirow[b]{2}{*}{$\begin{array}{l}\text { at the } \\
\text { baseline }\end{array}$} & Mean & 32.78 & 44.66 & \multirow[b]{2}{*}{0.003} & \multirow[b]{2}{*}{ Significant } \\
\hline & & $\begin{array}{l}\text { Standard } \\
\text { Deviation }\end{array}$ & 12.43 & 6.74 & & \\
\hline \multirow[b]{2}{*}{$\begin{array}{l}\text { RNFL total at } \\
\text { macula. }\end{array}$} & \multirow[b]{2}{*}{$\begin{array}{l}\text { at the } \\
\text { baseline }\end{array}$} & Mean & 35.43 & 51 & \multirow[b]{2}{*}{0.055} & \multirow[b]{2}{*}{ Not significant } \\
\hline & & $\begin{array}{l}\text { Standard } \\
\text { Deviation }\end{array}$ & 12.29 & 21.18 & & \\
\hline \multirow[b]{2}{*}{$\begin{array}{l}\text { RNFL superior } \\
\text { at macula. }\end{array}$} & \multirow[b]{2}{*}{ after 1 month } & Mean & 43.47 & 69 & \multirow[b]{2}{*}{0.6} & \multirow[b]{2}{*}{ Not significant } \\
\hline & & $\begin{array}{l}\text { Standard } \\
\text { Deviation }\end{array}$ & 12.77 & 36.95 & & \\
\hline \multirow{2}{*}{$\begin{array}{l}\text { RNFL inferior } \\
\text { at macula. }\end{array}$} & \multirow[b]{2}{*}{ after 1 month } & Mean & 42.95 & 62.5 & \multirow[b]{2}{*}{0.02} & \multirow[b]{2}{*}{ Significant } \\
\hline & & $\begin{array}{l}\text { Standard } \\
\text { Deviation }\end{array}$ & 14.80 & 19.99 & & \\
\hline \multirow[b]{2}{*}{$\begin{array}{l}\text { RNFL total at } \\
\text { macula. }\end{array}$} & \multirow[b]{2}{*}{ after 1 month } & Mean & 42.56 & 60.33 & \multirow[b]{2}{*}{0.06} & \multirow[b]{2}{*}{ Not significant } \\
\hline & & $\begin{array}{l}\text { Standard } \\
\text { Deviation }\end{array}$ & 13.23 & 10.92 & & \\
\hline \multirow{2}{*}{$\begin{array}{l}\text { RNFL superior } \\
\text { at macula. }\end{array}$} & \multirow{2}{*}{$\begin{array}{l}\text { after } 6 \\
\text { months }\end{array}$} & Mean & 40.82 & 66 & \multirow[b]{2}{*}{0.01} & \multirow[b]{2}{*}{ Significant } \\
\hline & & $\begin{array}{l}\text { Standard } \\
\text { Deviation }\end{array}$ & 12.16 & 36.76 & & \\
\hline \multirow[b]{2}{*}{$\begin{array}{l}\text { RNFL inferior } \\
\text { at macula. }\end{array}$} & \multirow[b]{2}{*}{$\begin{array}{l}\text { after } 6 \\
\text { months }\end{array}$} & Mean & 40.26 & 60.83 & & \\
\hline & & $\begin{array}{l}\text { Standard } \\
\text { Deviation }\end{array}$ & 15.16 & 20.72 & 0.01 & Significant \\
\hline & & Mean & 40.74 & 85.5 & & \\
\hline $\begin{array}{l}\text { RNFL total at } \\
\text { macula. }\end{array}$ & $\begin{array}{l}\text { atter } 6 \\
\text { months }\end{array}$ & $\begin{array}{l}\text { Standard } \\
\text { Deviation }\end{array}$ & 12.99 & 26.44 & 0.15 & Significant \\
\hline
\end{tabular}


Few studies have reported on the changes in macular GCL thickness and its relationship with RNFL thickness after laser.

In our study changes in RNFL and GCL were recorded in this study after both PRP and grid laser applications for DR. Changes in the RNFL and GCL are difficult to judge clinically and require an advanced investigation. Computerized quantitative RNFL and GCL analysis provides a more reliable assessment of early changes in RNFL and GCL thickness. The type and pattern of recorded changes varied according to the time after the laser therapy and the quadrant of the retina examined.

In our study although PRP has been proven to be an effective treatment strategy for severe DR, most ophthalmologists agree that the high laser intensity causes damage to the entire retinal layer and should be avoided. If the high-intensity laser beam causes destruction of the entire retinal layer, including the GCL, it will result in a loss of RNFL and cause a sequential decrease in the RNFL thickness. OCT measurements of the RNFL thickness showed a statistically significant thickening in the total RNFL 1 months after laser treatment followed by statistically significant reduction in the total RNFL thickness 6 months after laser treatment, indicating that the major reduction in RNFL thickness occurs at the time interval between 1 and 6 months following laser treatment. This reduction in the RNFL thickness varied from one retinal quadrant to another, with the most significant change taking place in both the nasal and the inferior quadrants. The temporal and superior quadrants were less affected and the change in the RNFL was found to be statistically nonsignificant. The very mild reduction in RNFL thickness in the temporal quadrant can be attributed to the sparing of the papillomacular bundle during application of laser treatment.

In this study we used a conventional argon $514 \mathrm{~nm}$ green laser which showed statistically significant increase of total RNFL thickness $(+9.03 \mu \mathrm{m} ; \mathrm{p}<0.05)$ at 1 month after photocoagulation, however significant reduction in total RNFL thickness $(-2.93 \mu \mathrm{m} ; \mathrm{p}<0.05)$ was measured after the sixth month of post treatment follow up. A statistically significant increase of superior RNFL thickness $(+11.97 \mu \mathrm{m} ; \mathrm{p}<0.05)$ at 1 month after photocoagulation, however a non-significant reduction in superior RNFL thickness $(-1.14 \mu \mathrm{m} ; \mathrm{p}>0.05)$ was measured after the sixth month of post treatment follow up. A statistically significant increase of inferior total RNFL thickness $(+11.07 \mu \mathrm{m} ; \mathrm{p}<0.05)$ at 1 month after photocoagulation, however significant reduction in inferior RNFL thickness $(-2.82 \mu \mathrm{m} ; \mathrm{p}<0.05)$ was measured after the sixth month of post treatment follow up.

In agreement with Muqit et al. (7) who prospectively evaluated the RNFL thickness alterations on 10 eyes with PDR after PRP treatment performed with argon $514 \mathrm{~nm}$ green laser. In order to measure
RNFL thickness in the peripapillary zone, the Stratus OCT3 system was used in their study. Authors reported statistically significant RNFL thickness increase $(+8$ $\mu \mathrm{m} ; \mathrm{p}<0.05)$ at 10 weeks after photocoagulation, however significant reduction in RNFL thickness (-4 $\mu \mathrm{m} ; \mathrm{p}<0.05$ ) was measured after the sixth month of post treatment follow up. They attributed the early thickening of RNFL following the PRP to inner retinal axon damage by thermal diffusion around the 100-ms burn, disruption of the mid-flow axonal flow and axonal edema $^{(7)}$.

In this study, on average, the RNFL thickened during the early post-PRP period. After 1 month postPRP, increasing trend in the total and in all quadrants of the RNFL thickness was observed. Then, the total, superior and inferior RNFL thickness measured 6 months after PRP decreased significantly. However, several previous studies showed that there were no significant changes in the RNFL thickness for the average, superior, inferior and nasal quadrants between the baseline and 1 year post-PRP ${ }^{(8,9)}$.

These inconsistent results could be explained by the use of different OCT systems. Compared with previous studies using Stratus OCT the RNFL thickness was measured using the spectral-domain OCT, which showed excellent reproducibility.

Nevertheless, this study we observed a significant reduction in RNFL thickness within each retinal quadrant at the 6 post-laser months compared to 1 month values except superior retina and this attributed to the sparing of the papillomacular bundle during application of laser treatment. Acute edema related increase in retinal thickness develops soon after the photocoagulation, and it may protect ganglion cells against the destructive effects of laser application, so retinal injury worsens in case of repetitious laser treatments with longer intervals.

However, in our study we used SD OCT which showed statistically significant decrease in RNFL thickness in all retinal quadrant except superior at 6 months of post laser follow up. This may be associated with a shorter laser exposure time and better focusing on the retina.

In addition, the results of this study showed that a reduction in the total RNFL thickness after 6 months of laser treatment, which was statistically significant. This is in agreement with $\mathbf{L i m}$ et al. ${ }^{\mathbf{( 1 0 )}}$, who studied 94 eyes of 48 healthy individuals, 89 eyes of 55 diabetic patients who did not undergo PRP and 37 eyes of 24 patients with diabetes who underwent PRP were included in this study. Eyes that had been treated with PRP had thinner peripapillary RNFL compared with the other groups; this was statistically significantly different in the inferior $(\mathrm{P}=0.004)$ and nasal $(\mathrm{P}=0.003)$ regions. Moreover, there was a statistically significant difference in RNFL thickness in the inferior and nasal peripapillary regions among the three groups when adjusted for study center, age, and race compared with normal eyes; those 
that had received PRP treatment had statistically significantly thinner RNFL measurements in the inferior $(P=0.001)$ and the nasal quadrant $(P=0.002)$. Thus, there was a significant reduction in RNFL thickness in the period between 1 and 6 months more than after 1 month after PRP ${ }^{(10)}$.

In this study, the GCL thickened during the early post-PRP period then decreased thereafter. These thickenings of the macular GCL could be explained by PRP-induced retinal inflammation and edema in the early post-PRP phase. A statistically significant increase of total GCL thickness $(+5.59 \mu \mathrm{m} ; \mathrm{p}<0.05)$ at 1 month after photocoagulation, however significant reduction in total GCL thickness $(-3 \mu \mathrm{m} ; \mathrm{p}<0.05)$ was measured after the 6 month of post treatment follow up. A statistically significant increase of superior GCL thickness $(+4.83 \mu \mathrm{m} ; \mathrm{p}<0.05)$ at 1 month after photocoagulation, followed by significant reduction in superior GCL thickness $(-2.31 \mu \mathrm{m} ; \mathrm{p}<0.05)$ at the sixth month was recorded.

The pattern of changes however is different in the inferior quadrant. The changes in thickness after 1 month is non-significant $(+3.31 \mu \mathrm{m} ; \mathrm{p}>0.05)$ while it is significant after 6 month $(-1.55 \mu \mathrm{m} ; \mathrm{p}<0.05)$

Tababat-Khani et al. ${ }^{(11)}$ found that focal/grid photocoagulation of CSMO did not affect retinal sensitivity for up to 2 years after the treatment, which is the longest follow-up reported so far. They studied consecutively recruited diabetic subjects with varying degrees of macular edema and VA, and the results indicated that focal/grid photocoagulation causes only minimal or no damage to the neuroretina ${ }^{(11)}$.

This transient retinal thickening was most likely due to post-laser inflammatory effects. An animal study by Nonaka $\boldsymbol{e t}$ al. ${ }^{(12)}$ suggested that PRP increases leucocyte rolling and aggravation in blood vessels. This leucocyte-endothelial reaction further contributes to the increase in retinal vessel permeability, which results in retinal swelling post laser treatment.

The limitations of this study are a small sample size. Further analysis of each retinal layer thickness would be necessary to evaluate the pathological changes of each retinal layer after PRP. Long-term follow-up would be necessary to investigate for more evaluation.

\section{CONCLUSION}

OCT is the most sensitive and quantitative test for the evaluation of retinal and especially macular edema. SD OCT devices help to make more precise assessment of GC and RNFL thickness with respect of retinal quadrants, as they provide high definition images of retinal layers.

PRP should be used to treat two key complications of DR: retinal neovascularization and macular edema. Laser photocoagulation is not indicated in mild and moderate NPDR but it may be indicated in the presence of suggestive signs of development of PDR.
In conclusion, increase in the macular GC thickness and RNFL at the 1 month of follow-up may be related to laser induced intraretinal inflammation which triggers increased capillary permeability and ensuing axonal edema due to the cytokine release. Significant GC and RNLF decrease at the sixth month of follow-up can be attributed to axonal loss secondary to direct or indirect effects of PRP treatment. SD OCT is a very valuable tool to document the RNFL thickness changes following the argon laser photocoagulation.

\section{REFERENCES}

1. Sepúlveda J, Murray C (2014): The state of global health in 2014. Science, 345: 1275-1278.

2. Carpineto P, Ciancaglini M, Zuppardi E et al. (2003): Reliability of nerve fiber layer thickness measurements using optical coherence tomography in normal and glaucomatous eyes. Ophthalmology, 110:190195.

3. Mwanza JC, Durbin MK, Budenz DL et al. (2011): Profile and predictors of normal ganglion cell-inner plexiform layer thickness measured with frequency-domain optical coherence tomography. Invest Ophthalmol Vis Sci., 52:7872-9.

4. Apple D, Goldberg M, Wyhinny G (1993): Histopathology and ultrastructure of the argon laser lesion in human retina and choroids vasculatures. AmJ Ophthalmol., 75:595-609.

5. Brooks DE, Komàromy $\mathrm{AM}$, Källberg $\mathrm{ME}$ (1999): Comparative retinal ganglion cell and optic nerve morphology. Vet Ophthalmol ., 2:3-11.

6. ETDRS-Group (1987): Treatment techniques and clinical guidelines for photocoagulation of diabetic macular edema. Early Treatment Diabetic Retinopathy Study Report Number 2.Early Treatment Diabetic Retinopathy Study Research Group. Ophthalmology, 94: 761774.

7. Muqit MM, Wakely L, Stanga PE et al. (2010): Effects of conventional argon panretinal laser photocoagulation on retinal nerve fiber layer and driving visual fields in diabetic retinopathy. Eye (Lond), 24:11361142.

8. Kim J, Woo SJ, Ahn J et al. (2012): Longterm temporal changes of peripapillary retinal nerve fiber layer thickness before and after panretinal photocoagulation in severe diabetic retinopathy. Retina, 32:2052-60.

9. Lee SB, Kwag JY, Lee HJ et al. (2013): The longitudinal changes of retinal nerve fiber layer thickness after panretinal photocoagulation in 
diabetic retinopathy patients. Retina, 33:18893.

10. Lim MC, Tanimoto SA, Furlani BAL et al. (2009): Effect of diabetic retinopathy and panretinal photocoagulation on retinal nerve fiber layer and optic nerve appearance. Arch Ophthalmol., 127:857-862.

11. Tababat-Khani $P$, Bengtsson $B$, Agardh $E$ (2016): Effects of focal/grid laser treatment on the central visual field in diabetic macular oedema: a 2-yearfollow-up study. Acta Ophthalmol., 94: 240-245.

12. Nonaka A, Kiryu J, Tsujikawa A et al. (2002): Inflammatory response after scatter laser photocoagulation in non-photocoagulated retina. Invest Ophthamol Vis Sci., 43(4): 12049. 